\title{
Gestão do desenvolvimento de produto em empresas de pequeno e médio porte do setor de máquinas e implementos agrícolas do Estado de SP
}

\author{
Product development process management in small and \\ medium-sized Brazilian companies in the agricultural \\ machinery and implement industry sector
}

\author{
José Carlos de Toledo' \\ Julianita Maria Scaranello Simões ${ }^{1}$
}

\begin{abstract}
Resumo: Para que as empresas nacionais do setor de máquinas e implementos agrícolas consigam sobreviver e ampliar sua participação nesse mercado em crescimento, do interesse econômico de companhias multinacionais e no qual essas detêm expressiva participação, elas necessitam melhorar a capacitação para desenvolver novos produtos e assim atender as novas demandas quanto a requisitos e homologação dessa produção. As empresas nacionais do setor apresentam um perfil predominante de empresas familiares, de pequeno e médio porte, e pouco se conhece sobre a realidade da gestão do Processo de Desenvolvimento de Produto (PDP) nessas organizações. Este trabalho caracteriza e analisa os perfis e a maturidade da gestão do PDP em empresas de pequeno e médio porte de capital nacional do segmento de máquinas e implementos agrícolas do Estado de São Paulo. Foi realizada uma pesquisa de levantamento (survey) em 40 empresas. Para a análise dos dados utilizou-se a técnica de análise multivariada de clusters. As empresas da amostra apresentam uma estrutura heterogênea com relação à gestão do PDP. Foram identificados três grupos de empresas, com diferentes perfis de maturidade do PDP: Grupo I (20\% da amostra), Grupo II (50\% da amostra) e Grupo III (30\% da amostra). Evidenciam-se diferenças na gestão do PDP principalmente entre os Grupos I (com menor nível de maturidade do PDP) e III (com nível de maturidade relativamente mais elevado). Apesar das diferenças na gestão do PDP entre os grupos, comparando-se a prática com o referencial teórico (as boas práticas sobre gestão do PDP), os 3 grupos se encontram no nível geral básico, ou inicial, de maturidade do PDP. A análise e identificação do nível de maturidade em que as empresas se encontram podem auxiliar no direcionamento do processo de melhoria do PDP e na elaboração de políticas públicas que incentivem o desenvolvimento e inovação de produto nas empresas nacionais do setor.
\end{abstract}

Palavras-chaves: Gestão do Processo de Desenvolvimento de Produto. Desenvolvimento de produtos. Máquinas e implementos agrícolas. Pequenas e médias empresas.

\begin{abstract}
The product development process (PDP), if well-structured and managed, can become a business process that directly influences the companies' competitiveness increase. The PDP in Brazilian SMEs in the agricultural machinery and implement industry Sector (AMI) is little known since most publications on product development focuses on the reality of large and multinational companies, which have a quite different structure from SMEs. The purpose of this paper is to characterize and analyze the management maturity profiles of the product development process in small and medium sized Brazilian companies in the agricultural machinery and implement industry sector located in the state of São Paulo. Therefore, the addressed actions of PDP improvements in those companies can be undertaken. A survey research was conducted in 40 companies. An in loco interview was applied to the respective individual in-charge of PDP by means of a structured questionnaire. For the data analysis, descriptive statistics and the multivariate cluster analysis techniques were used. The findings indicated that the SMEs in AMIs of the state of Sao Paulo present a heterogeneous structure with respect to PDP management. Three groups of companies were identified in the sample with different maturity PDP profiles: Group I (20\% of companies in the sample), Group II (50\% of the sample), and Group III (30\% of the sample). Differences in the management of PDP were observed, especially among companies of Group I (smallest level of PDP maturity) and Group III (highest level of PDP maturity). However, despite the differences in PDP management presented in the groups of companies, according to the literature on PDP management, all groups are in the basic (initial) maturity level of PDP. The identification of the maturity level, in which these companies are, can help the determination of activities that link the internal actions to improve the PDP of these companies and the proposal of specific public policies that encourage the improvement of product development for domestic companies in this industry sector.
\end{abstract}

Keywords: PDP management. Product development. Agricultural machines and implements. Small and medium enterprises.

\footnotetext{
Grupo de Estudo e Pesquisa em Qualidade - GEPEQ, Departamento de Engenharia de Produção - DEP, Universidade Federal de São Carlos - UFSCar, Rodovia Washington Luiz, km 235, CEP 13565-905, CP 676, São Carlos-SP, Brasil, email: toledo@ufscar.br Recebido em 16/10/2010 — Aceito em 11/5/2010
}

Suporte financeiro: FAPESP. 


\section{Introdução}

O agronegócio tem apresentado um significativo destaque na economia brasileira, especialmente no período 1999 a 2005 (CONFEDERAÇÃO DA AGRICULTURA E PECUÁRIA DO BRASIL CNA; CENTRO DE ESTUDOS AVANÇADOS EM ECONOMIA APLICADA - CEPEA, 2005). De acordo com o Ministério da Agricultura Pecuária e Abastecimento - MAPA (BRASIL, 2004), a evolução do agronegócio brasileiro está diretamente associada ao desenvolvimento científico-tecnológico, à modernização da atividade rural, à expansão da indústria de máquinas e implementos agrícolas, à adoção de programas de sanidade animal e vegetal e à modernização das políticas agrícolas.

O setor de máquinas e implementos agrícolas (MIAs), cujo desempenho está diretamente relacionado ao desempenho da agricultura e à disponibilidade de crédito agrícola para investimentos (BRASIL, 2006), apresentou uma grande expansão no mesmo período (1999 a 2005), acompanhando o desenvolvimento do agronegócio.

Segundo a Associação Brasileira da Indústria de Máquinas e Equipamentos - ABIMAQ (2005), o faturamento interno nominal do setor de máquinas e implementos agrícolas aumentou cerca de $100 \%$ entre 2000 e 2004, passando de U\$ 1,1 bilhão em 2000 para U\$ 2,2 bilhões em 2004. As exportações também aumentaram significativamente, passando de U\$ 125 milhões em 2000 para U\$ 536 milhões em 2004.

No entanto, de acordo com Associação Brasileira da Indústria de Máquinas e Equipamentos - ABIMAQ (2006), no período 2005-2006 o número de máquinas e implementos agrícolas produzidos no país diminuiu bruscamente, em função da redução da safra nacional de grãos (devido à seca que assolou a região Sul do país), da redução dos preços das commodities no mercado internacional, especialmente dos produtos do complexo soja, e da valorização do real no período. A partir de 2007, esse cenário começou a se modificar com a recuperação dos preços, em especial, da cana-de-açúcar, da soja e do milho, e também com o aumento no volume da safra.

$\mathrm{O}$ aumento da competitividade das máquinas e implementos agrícolas produzidas pela indústria nacional, para manter a sua competitividade no setor, requer melhorias no projeto e no Processo de Desenvolvimento de Produtos dessas empresas. As empresas nacionais deste segmento são essencialmente de pequeno e médio porte e com tradição de gestão familiar.

Segundo Clark e Fujimoto (1991), Wheelwright e Clark (1992) e Rozenfeld et al. (2006), o Processo de Desenvolvimento de Produto (PDP), se bem estruturado e gerenciado, é fundamental para a competitividade sustentada das empresas que atuam nos mercados interno e externo, como é o caso da indústria de máquinas e implementos agrícolas.

Entretanto, pouco se conhece sobre o Processo de Desenvolvimento de Produto nas empresas nacionais do setor. As publicações sobre o PDP, na sua maioria, focam a realidade das grandes empresas e de empresas multinacionais, principalmente do setor automobilístico, organizações que possuem uma estrutura bastante diferenciada em relação às PMEs.

Este trabalho objetiva caracterizar e analisar os perfis da gestão e da maturidade do Processo de Desenvolvimento de Produto em empresas de pequeno e médio porte de capital nacional do setor de máquinas e implementos agrícolas do Estado de São Paulo.

A identificação da maturidade do PDP, nessas empresas, se justifica, uma vez que possibilita que ações de melhoria para a gestão doesse processo, de iniciativa das empresas ou induzidas por instituições governamentais, sejam direcionadas de acordo com as reais necessidades delas.

O Estado de São Paulo foi definido como escopo geográfico da pesquisa de campo, pois, de acordo com IBGE (BRASIL, 2005), São Paulo é um dos estados que concentra o maior número de fabricantes de máquinas e implementos agrícolas no Brasil. $\mathrm{O}$ foco nas pequenas e médias empresas (PMEs) deve-se a que, no Brasil, a produção de MIAs se concentra principalmente nas PMEs de capital nacional (ROMANO, 2003).

\section{Gestão do Processo de Desenvolvimento de Produto}

De acordo com Toledo et al. (2006), o Processo de Desenvolvimento de Produto é um importante processo de negócio que influencia diretamente no aumento da competitividade das empresas. O PDP situa-se na interface entre a empresa e o mercado, identificando as reais e futuras necessidades do mercado e procurando atendê-las por meio do desenvolvimento de novos produtos. É por meio desse processo que, no presente, se desenvolvem os produtos a serem manufaturados e que no futuro irão assegurar o faturamento da empresa.

Para Rozenfeld et al. (2006), o PDP consiste em uma série de atividades que se iniciam com a análise das necessidades do mercado, das possibilidades tecnológicas e dos recursos, e que devem estar alinhadas aos objetivos estratégicos das empresas. Abrange as atividades de elaboração das especificações de projeto do produto e de seu processo de produção e finaliza com as atividades de acompanhamento do produto no mercado, após o seu lançamento, para identificar eventuais mudanças necessárias, e com as atividades de descontinuidade do produto no mercado. 
O PDP exerce influência e é influenciado em todas as fases do ciclo de vida do produto, da concepção ao descarte e retirada do produto do mercado.

Para Rozenfeld et al. (2006), as atividades do PDP podem ser agrupadas em três macrofases: pré-desenvolvimento, desenvolvimento e pós-desenvolvimento. O pré-desenvolvimento envolve as fases de planejamento estratégico do produto e de planejamento do projeto. Esta macrofase tem por objetivo definir o portfolio de produtos da empresa baseado no plano estratégico da corporação, nas ideias de novos produtos vindas de fontes internas e externas à empresa, nas oportunidades (de mercado e tecnológicas) e nas restrições (por exemplo, de capital e de capacidade de produção). A macrofase de desenvolvimento é composta pelas fases: projeto informacional, projeto conceitual, projeto detalhado, preparação da produção e lançamento do produto. Durante esta macrofase são estabelecidas as especificações: de projeto, do produto, do processo de produção, do processo de manutenção, do processo de vendas, do processo de distribuição, do processo de assistência técnica e do processo de atendimento ao cliente. A macrofase de pós-desenvolvimento engloba as fases: acompanhar o desempenho produto e do seu processo de produção e decidir e acompanhar a descontinuidade do produto. Nesta macrofase, a partir das lições aprendidas, se identificam as oportunidades de melhoria no produto, no processo produtivo e no PDP da empresa.

De acordo com Clark e Fujimoto (1991), Wheelwright e Clark (1992) e Rozenfeld et al. (2006), o bom desempenho do PDP depende, em grande parte, da maneira como este processo é gerenciado. Dentre as práticas que contribuem para uma gestão eficiente e eficaz do PDP destacam-se: visão do desenvolvimento de produto como um processo de negócio; alinhamento entre as atividades de desenvolvimento de produto e o planejamento estratégico da empresa; o gerenciamento do ciclo de vida de produtos; a adoção de um modelo que define, de maneira geral, em manuais e procedimentos, as atividades que devem ser realizadas ao longo do PDP; o envolvimento de profissionais das diversas áreas funcionais envolvidas no PDP (times multifuncionais de projeto); o envolvimento de parceiros (fornecedores, clientes, universidades, institutos de tecnologia etc.) durante o PDP; o uso de métodos e técnicas de suporte ao PDP; a realização de reuniões de avaliação das atividades e resultados (gates) ao longo do PDP; o uso de indicadores para avaliar e melhorar o desempenho dos projetos e do PDP; a utilização de mecanismos formais para registrar as lições aprendidas nos projetos realizados; e a abordagem de gestão da evolução do PDP por meio de níveis de maturidade.

Tendo em vista o amplo escopo do PDP (CHENG, 2000; ROZENFELD; AMARAL; TOLEDO, 2000; KAHN; BARCZAK; MOSS,
2006; PRODUCT DEVELOPMENT AND MANAGEMENTASSOCIATION, 2007), ele pode ser visualizado a partir de um conjunto de dimensões (visões ou enfoques) que possibilitam compreender a situação do PDP numa empresa e direcionar ações de melhoria.

De maneira geral, as dimensões do PDP propostas por diversos autores e entidades da área são semelhantes, alterando-se, em geral, a nomenclatura da dimensão e os itens considerados em cada uma delas.

Segundo os autores existiriam quatro dimensões básicas por meio das quais o PDP pode ser avaliado:

- Estratégica: que engloba a gestão do portfolio de produtos e de projetos da empresa, avaliação do desempenho do PDP, a decisão sobre alianças e parcerias e a condução das relações interfuncionais na empresa;

- Organizacional: que envolve a estrutura organizacional adotada para o PDP e para a gestão dos times de desenvolvimento, incluindo o papel dos líderes dos projetos e os programas de capacitação e de acompanhamento da qualificação do pessoal envolvido;

- Atividades e informações: relaciona-se a todas as atividades realizadas durante o PDP e ao gerenciamento das informações necessárias e das geradas durante este processo; e

- Métodos e recursos: refere-se aos métodos, técnicas, ferramentas e sistemas que podem ser aplicados como apoio em uma ou mais das dimensões anteriores e na realização de atividades específicas (por ex.: avaliação de protótipos, testes de campo etc.).

Na bibliografia sobre níveis de maturidade para o PDP (CHRISSIS; KONRAD; SHRUM, 2003; ROZENFELD et al., 2006), consideram-se três elementos para se avaliar o grau de maturidade deste processo:

- Quais fases, atividades e tarefas são realizadas pela empresa;

- Como são realizadas essas atividades (métodos e ferramentas utilizados); e

- Em que etapa do ciclo incremental de evolução do PDP (padronização do processo, medição, controle do processo e melhoria contínua) a empresa se encontra.

São definidos cinco níveis de maturidade:

- Nível 1 - Básico: Indica que apenas algumas atividades das prescritas como boas práticas na bibliografia e nos manuais sobre PDP são realizadas;

- Nível 2 - Intermediário: As atividades do PDP são padronizadas e seus resultados são 
previsíveis. Métodos e ferramentas consagradas de apoio ao PDP são utilizados;

- Nível 3 - Mensurável: Engloba a realização de todas as atividades dos níveis anteriores, acrescentando-se o uso de indicadores de desempenho para medir o desempenho das atividades. No entanto, as ações de correção e melhoria do processo não são sistemáticas;

- Nível 4-Controlado: Abrange todos os níveis anteriores. As ações de correção são sistemáticas e integradas aos processos de gerenciamento de mudança e de melhoria incremental do PDP; e

- Nível 5 - Melhoria Contínua: Engloba as atividades dos níveis anteriores. Ocorre a integração interna ao PDP, e deste com os processos de: gerenciamento das mudanças de engenharia, melhoria incremental do PDP e processo de transformação do PDP. A prática de permanente melhoria no PDP como um todo é contínua e incorpora-se à cultura da empresa e da área.

De acordo com a realidade e necessidades da empresa, práticas de diferentes níveis de maturidade podem ser utilizadas simultaneamente. A adoção ou não de uma determinada atividade ou prática do PDP depende da sua adequação às condições da empresa, bem como da capacitação da organização para implementá-la.

\section{O setor de máquinas e implementos agrícolas}

Conforme Amato Neto (1984), BNDES (BRASIL, 1995) e Romano (2003), a indústria de máquinas e implementos agrícola, no Brasil, apresenta desde suas origens uma estrutura bastante heterogênea. De acordo com o Ministério da Ciência e Tecnologia MCT (BRASIL, 1993), as empresas do setor se diferenciam segundo o tamanho, grau de complexidade do produto, grau de complexidade do sistema produtivo e gerencial, canais de suprimentos e distribuição, grau de diversificação da empresa e escopo de mercado.

Segundo Romano (2003), essas empresas apresentam, em sua maioria, as seguintes características:

- São empresas familiares ou ainda em fase de transição para uma gestão mais profissional;

- Focam na diversificação de seus produtos e em inovações adaptativas;

- Apresentam baixo volume de produção por tipo de equipamento, se comparadas, por exemplo, à indústria automobilística;

- Enfrentam forte sazonalidade da demanda; e

- Apresentam a necessidade de desenvolver soluções específicas para atender uma grande variedade de tipos de lavoura, solo, topografia, condições

climáticas e de mão-de-obra rural no país.

Atualmente, as máquinas e implementos agrícolas estão presentes na realização de todas as atividades agropecuárias, do preparo do solo ao armazenamento e transporte dos produtos, variando desde ferramentas manuais até produtos com tecnologia de ponta para a mecanização e automação, e atendendo as necessidades de pequenos, médios e grandes produtores (BRASIL, 2006).

Com relação à tecnologia incorporada aos produtos, observa-se a adoção não somente de técnicas que otimizam os processos da máquina em si, tais como GPS, tecnologia de agricultura de precisão, etc., mas que também auxiliam no gerenciamento da propriedade rural, fornecendo informações para a tomada de decisões.

No entanto, apesar da melhoria das tecnologias das MIAs brasileiras e do crescimento do setor no país, Romano (2003), em pesquisa realizada na região Sul, considera que o PDP nessas empresas apresenta uma série de deficiências que afetam o desempenho nos mercados interno e externo. Dentre elas, destaca:

- A ausência de documentação que defina as atividades do PDP nas empresas de pequeno e médio porte, sendo este processo realizado de modo informal e sequencial, de acordo com a experiência dos responsáveis;

- A realização do PDP de modo formal se dá apenas nas empresas de grande porte, sendo este feito em alguns momentos de maneira sequencial e, em outros, de maneira simultânea;

- A adoção da estrutura organizacional funcional (departamental) nas empresas; e

- Foco no desenvolvimento de projetos derivativos (aperfeiçoamento de produtos existentes) e adaptativos.

Essas deficiências se manifestam mais acentuadamente nas pequenas e médias empresas, uma vez que estas frequentemente enfrentam limitações técnicas, financeiras e de pessoal, o que influencia diretamente no gerenciamento e estruturação do PDP. Assim, justifica-se conhecer a realidade do PDP e de sua gestão nas pequenas e médias empresas nacionais do setor de máquinas e implementos agrícolas, bem como identificar as limitações gerenciais que dificultam uma maior e melhor capacitação para desenvolvimento de novos produtos. Espera-se contribuir para que essas empresas consolidem e ampliem sua atuação nos mercados interno e externo, melhorando sua estrutura organizacional e desempenho.

\section{Método de pesquisa}

A pesquisa realizada é do tipo descritiva-quantitativa, baseando-se no método survey. O instrumento de coleta 
de dados utilizado foi um questionário estruturado aplicado in loco, em visitas às empresas.

A pesquisa iniciou-se com uma revisão bibliográfica sobre gestão do PDP e sobre a indústria de máquinas e implementos agrícolas no Brasil. Posteriormente, elaborou-se uma primeira versão do questionário e realizou-se a validação do mesmo em três empresas, e, paralelamente, procedeu-se à adequação do questionário e à identificação do universo de empresas de máquinas e implementos agrícolas de capital nacional no Estado de São Paulo. Foram identificadas 120 empresas de pequeno e médio porte no Estado, por meio de listas da ABIMAQ, de catálogos da Agrishow e de sites do setor.

Foi definido um tamanho de amostra de 40 empresas, o que representa um terço do universo de pequenas e médias empresas identificado no Estado. Procurou-se selecionar e levantar dados de empresas localizadas em diferentes regiões do Estado e estratificadas por porte (pequeno ou médio). Algumas empresas selecionadas não aceitaram participar da pesquisa e foram substituídas por outras da mesma região. Das 40 empresas que participaram, 25 são de pequeno porte (até 99 funcionários) e 15 de médio porte (entre 100 e 499 funcionários).

Por meio de contato telefônico verificou-se se a empresa se enquadrava no perfil definido para a pesquisa de campo. Em seguida agendou-se uma visita e entrevista com o responsável pelo desenvolvimento de produto, para aplicação do questionário. A duração média das entrevistas foi de cerca de duas horas e meia.

Após a inserção da resposta aos 40 questionários num banco de dados e compilação das informações, foi realizada a análise de clusters, com o auxílio do software Statistica versão 7, a fim de analisar e caracterizar os perfis de gestão do PDP e sua associação a níveis de maturidade existentes nas empresas da amostra. Também foram realizadas outras análises estatísticas que estão fora do escopo deste artigo.

A característica de referência para análise e agrupamento foi o grau de formalismo (institucionalização) das atividades do PDP realizadas pelas empresas. Esta característica foi escolhida uma vez que as publicações sobre gestão e maturidade do PDP consideram como importante dimensão de análise a definição e formalização das fases, atividades e tarefas realizadas. Essa recomendação básica seria aplicável inclusive a empresas de menor porte, tendo em vista que o desenvolvimento de novos produtos requer disciplina na realização das atividades de projeto e no registro de informações para validação e homologação de produtos, para rastreabilidade e comprovação de atendimento a requisitos dos clientes e a normas de desempenho e segurança e para aprendizagem, a ser incorporada, ou não, a futuros projetos. A realização das atividades do PDP, de maneira formal ou não, gera uma determinada estruturação, que acaba por influenciar o desempenho do PDP. É importante ressaltar que a formalização aqui considerada refere-se a atividades de projeto e engenharia de novos produtos.

Para definição dos clusters foi utilizado o Método de Ward, que se mostrou capaz de descrever melhor os dados. Tendo por base as respostas obtidas para as questões relativas à estruturação e formalização das atividades do PDP, foi realizada no software Statistica a análise de cluster por k-means, que forma os agrupamentos com base na média das respostas. Optou-se pela formação de três agrupamentos de empresas.

Posteriormente foi realizado um workshop com profissionais das empresas que participaram da pesquisa de campo, a fim de discutir, avaliar e validar os resultados das análises, além de se pensar conjuntamente em possíveis ações para melhoria do PDP.

\section{Apresentação dos resultados}

Com o objetivo de agrupar as empresas em função do nível de estruturação da gestão do PDP, foi realizada a análise de clusters. A análise resultou em três agrupamentos de empresas: o Grupo I é o menor, compõe-se de $20 \%$ das empresas da amostra; o Grupo II, de 50\% das empresas; e o Grupo III, de 30\%.

Como o grau de estruturação e formalização das atividades do PDP foi a variável utilizada para gerar os agrupamentos, procurou-se verificar se, baseado neste critério, os grupos gerados apresentavam diferenças entre si.

De acordo com a Figura 1, as empresas do Grupo I não realizam algumas atividades do PDP, normalmente sugeridas na bibliografia (37\% das atividades listadas no questionário a partir de propostas de modelos básicos para desenvolvimento de novos produtos considerando setores industriais com predominância de tecnologias maduras não são realizadas por essas empresas), ou as realizam de maneira informal (50\% das atividades). No Grupo II, $42 \%$ das atividades do PDP são realizadas de maneira formal, $39 \%$

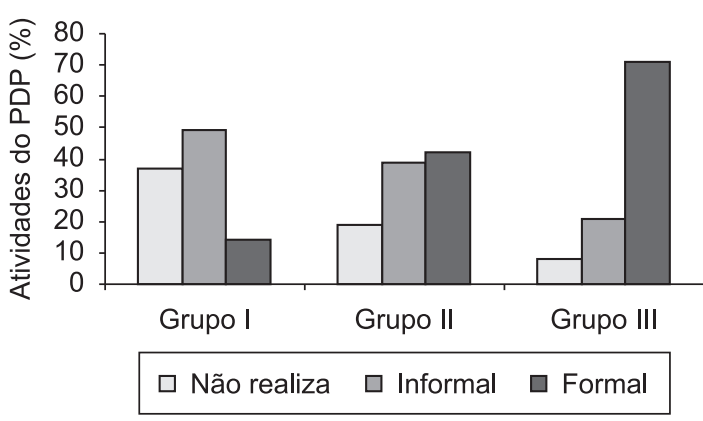

Figura 1. Grau de formalismo das atividades do PDP. 
são realizadas de maneira informal e 19\% não são realizadas. No Grupo III, as atividades propostas no questionário são realizadas predominantemente de maneira formal (70\% das atividades). Isso evidencia um crescimento na realização e formalização das atividades do PDP na direção do Grupo I para o Grupo III.

A seguir são apresentadas outras diferenciações entre os grupos, associadas a características gerais das empresas e à gestão do PDP.

\subsection{Caracterização geral dos grupos}

No Grupo I, todas as empresas são de pequeno porte. No Grupo II predominam as empresas de pequeno porte (65\% das organizações) e, no Grupo III, a maioria das empresas é de médio porte $(67 \%$ delas), conforme a Tabela 1.

O faturamento médio nas empresas do Grupo I, nos últimos 3 anos, é inferior a R \$ 25 milhões, com maior concentração de empresas entre $\mathrm{R} \$ 1$ milhão e R \$ 10 milhões. No Grupo II há também uma concentração do faturamento na faixa de $\mathrm{R} \$ 1$ milhão a R\$ 10 milhões, no entanto as demais empresas do Grupo tiveram faturamento entre R\$ 10 milhões e R \$ 75 milhões. O faturamento médio do Grupo III é distribuído de forma mais pulverizada, destacando-se uma faixa mais ampla de $\mathrm{R} \$ 5$ a 50 milhões e apresentando empresas com faturamento em faixas maiores (Figura 2).

Tabela 1. Porte das empresas por grupo.

\begin{tabular}{ccc}
\hline & \multicolumn{2}{c}{ Porte (\% } \\
\hline Grupo & Pequeno & Médio \\
\hline I & 100 & 0 \\
II & 65 & 35 \\
III & 33 & 67 \\
\hline
\end{tabular}

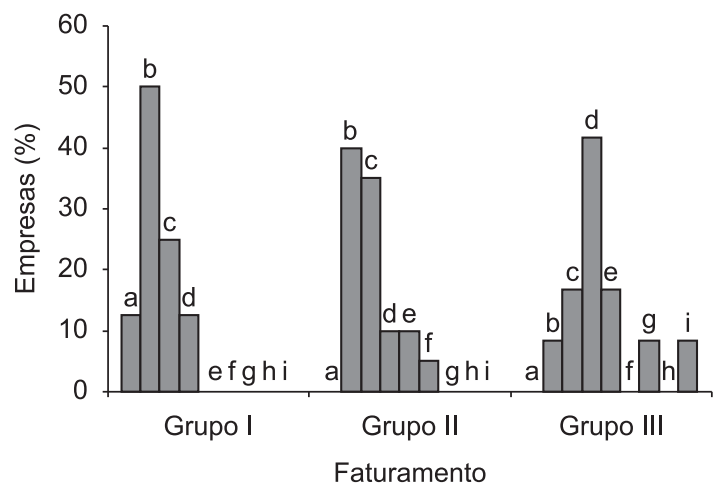

Figura 2. Faturamento médio anual das empresas por grupo. (F: Faturamento; mi: milhão - a: F $\leq \mathrm{R} \$ 1 \mathrm{mi}$; b: R\$ $1 \mathrm{mi}$ $<\mathrm{F} \leq \mathrm{R} \$ 5 \mathrm{mi}$; $\mathrm{c}$ R $\$ 5 \mathrm{mi}<\mathrm{F} \leq \mathrm{R} \$ 10 \mathrm{mi}$ d: R\$ $10 \mathrm{mi}<\mathrm{F}$ $\leq \mathrm{R} \$ 25 \mathrm{mi}$; e: $\mathrm{R} \$ 25 \mathrm{mi}<\mathrm{F}<\mathrm{R} \$ 50 \mathrm{mi}$; $\mathrm{f}$ R $\$ 50 \mathrm{mi}<\mathrm{F} \leq$ R\$ 75 mi; g: R\$ 75 mi < F $\leq$ R \$ 100 mi; h: F > R \$ $100 \mathrm{mi}$; i: Não informado).
No Grupo I, os produtos das empresas são focados principalmente nas atividades de preparo do solo. A alternativa "Outra atividade da produção agropecuária", no Grupo I, inclui: produtos destinados a avicultura e linha verde. No Grupo III, os produtos estão voltados principalmente para a etapa de colheita e a alternativa "Outra atividade da produção agropecuária" inclui produtos destinados a suinocultura e avicultura. No Grupo II, as linhas de produtos são mais diversificadas, estando distribuídas por todas as atividades da produção agropecuária, sendo que a alternativa "Outra atividade da produção agropecuária" inclui equipamentos voltados para o tratamento de sementes e poda de citros e café (Figura 3 ).

A porcentagem de empresas que exportam no Grupo II (90\% das empresas) e no Grupo III (83\% das empresas) é próxima, diferenciando-se da porcentagem de empresas que exportam no Grupo I (50\% das empresas). No entanto, a contribuição da exportação no faturamento das empresas é o dobro no Grupo III (16\%) em relação aos Grupos I (8\%) e II (8\%), o que indica que a quantidade de produtos exportados e/ ou o valor agregado destes no Grupo III são maiores que nos Grupo I e II. O faturamento do Grupo III é maior do que nos outros dois grupos, o que torna o volume financeiro ainda maior.

As empresas da amostra que afirmaram ter certificação ISO 9001 (3 empresas), ou estar em processo de certificação (1 empresa), pertencem ao Grupo III. A exportação, presente em maior escala nas empresas do Grupo III, estimula a busca dessa certificação.

Analisando-se os tipos de sistemas, subsistemas e componentes (SSCs) dos produtos das empresas, observa-se que nas empresas do Grupo I predominam os SSCs mecânicos, no Grupo II, os SSCs mecânicos,

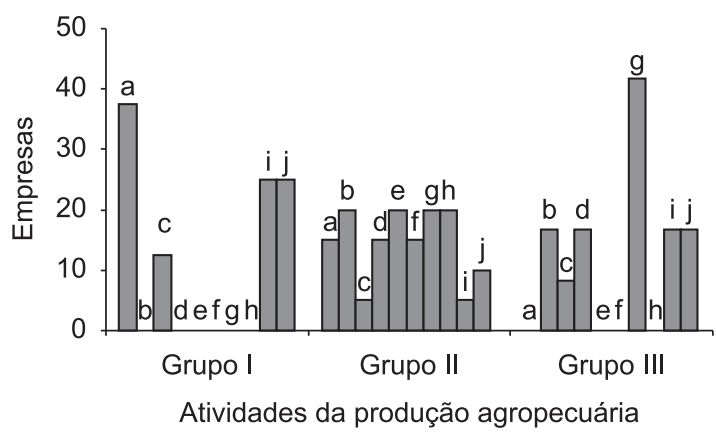

Figura 3. Etapas da produção agropecuária para as quais os produtos das empresas estão voltados, por grupo. (a: preparo do solo; b: semeadura e plantio; c: adubação; d: cultivo; e: aplicação de defensivos; f: irrigação; g: colheita; h: transporte e movimentação; i: beneficiamento; $\mathbf{j}$ : outra atividade da produção agropecuária). 
elétricos, eletrônicos e hidráulicos e, no Grupo III, prevalecem os SSCs mecânicos, elétricos e hidráulicos (Figura 4). Observa-se certa homogeneização e pulverização nos tipos de tecnologia adotada.

\subsection{Tipos de projetos}

Com relação aos tipos de projetos desenvolvidos pelas empresas nos últimos 3 anos, as empresas dos três grupos empreenderam esforços para desenvolver projetos inovadores para a organização, além de projetos plataforma e incrementais (Tabela 2). Os projetos de produtos inovadores para o mercado mereceram, relativamente, mais esforços de desenvolvimento no Grupo II.

Os projetos do tipo incremental foram os mais desenvolvidos pelas empresas dos três grupos. Nas empresas dos Grupos I e III, a quantidade de projetos desenvolvidos nos últimos três anos foi superior às do Grupo II. A quantidade de adaptações em produtos existentes que praticamente não exigiram alterações no projeto do produto é semelhante entre as empresas dos 3 grupos (Tabela 2).

As principais fontes de novas ideias utilizadas para desenvolvimento de novos produtos, para os três grupos, são as mesmas: clientes usuários finais, concorrentes e visitas a feiras e exposições.

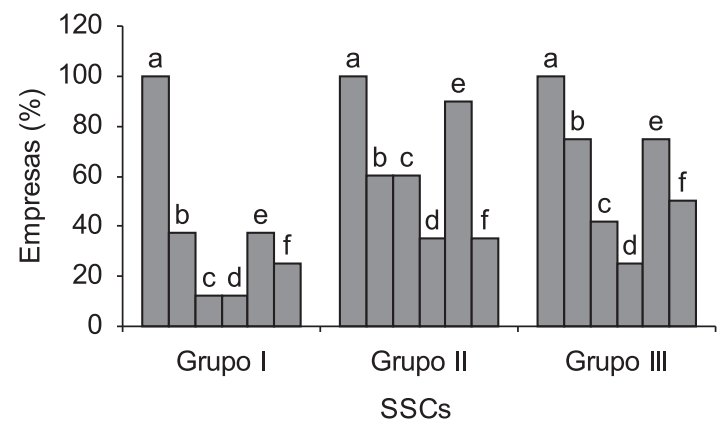

Figura 4. SSCs presentes nos produtos das empresas. (a: mecânica; b: elétrica; c: eletrônica; d: software; e: hidráulica; f: pneumática).

\subsection{Dimensões da gestão do Processo de Desenvolvimento de Produto}

\section{Dimensão estratégica}

A gestão de portfolio de produtos e projetos é desconhecida por cerca de $50 \%$ das empresas do Grupo III, 70\% das empresas do Grupo II e 87,5\% do Grupo I, sendo que apenas um terço das empresas do Grupo III realizam essa gestão.

A pesquisa de mercado é realizada por $83,3 \%$ das empresas do Grupo III, $60 \%$ das empresas do Grupo II e 37,5\% do Grupo I.

Com relação à porcentagem de empresas que utilizam indicadores para avaliar o desempenho do PDP, observa-se um aumento do Grupo I para o Grupo III, sendo que no Grupo I nenhuma empresa os utiliza, no Grupo II apenas $10 \%$ das empresas o fazem e, no Grupo III, cerca de $17 \%$ das empresas os utilizam. De modo geral, poucas empresas utilizam indicadores de desempenho como instrumento de gestão deste processo.

\section{Dimensão da organização}

Com relação à posição do PDP no organograma das empresas, os grupos basicamente não se diferenciam pois, em todos, o desenvolvimento de produto constitui uma área própria vinculada diretamente à presidência ou diretoria ou, então, um setor vinculado à área de engenharia.

As empresas do Grupo III mantêm o maior número de funcionários diretamente vinculados ao desenvolvimento de produto, sendo também o Grupo que proporcionalmente apresenta o maior número desses profissionais com formação superior (31\% dos 9,4), conforme Tabela 3. Isso pode estar relacionado ao tipo de produtos desenvolvidos pelas empresas deste grupo (voltados principalmente para a colheita) que, por serem mais complexos, demandam um número de profissionais maior e mais qualificado para desenvolvê-los.

Em média, as empresas do Grupo III conduzem ao mesmo tempo cerca de 5,3 projetos, as do Grupo II, 4,2 projetos e as do Grupo I, 1,5 projetos.

Tabela 2. Número médio de projetos desenvolvidos nos útimos três anos.

\begin{tabular}{lcccccc}
\hline Grupo & \multicolumn{5}{c}{ N. $^{\mathbf{0}}$ médio de projetos realizados } \\
\cline { 2 - 7 } & $\begin{array}{c}\text { Projetos de } \\
\text { produtos } \\
\text { inovadores } \\
\text { para o mercado }\end{array}$ & $\begin{array}{c}\text { Projetos de } \\
\text { produtos } \\
\text { inovadores } \\
\text { para a empresa }\end{array}$ & $\begin{array}{c}\text { Projetos de } \\
\text { produtos } \\
\text { plataforma }\end{array}$ & $\begin{array}{c}\text { Projetos de } \\
\text { produtos } \\
\text { derivados e } \\
\text { incrementais }\end{array}$ & $\begin{array}{c}\text { Adaptações sem } \\
\text { alteração de } \\
\text { projeto }\end{array}$ & $\begin{array}{c}\text { Total, em } \\
\text { média, de } \\
\text { projetos }\end{array}$ \\
\hline I & 1,0 & 3,7 & 2,8 & 31,6 & 14,0 & 53,1 \\
II & 2,5 & 3,8 & 6,8 & 11,2 & 15,3 & 39,6 \\
III & 1,5 & 3,5 & 4,2 & 37,7 & 15,0 & 61,9 \\
Total & 5,0 & 11,0 & 13,8 & 80,5 & 44,3 & 154,6 \\
\hline
\end{tabular}


Os 3 grupos não apresentam diferença considerável quanto ao número médio de equipes que trabalham simultaneamente no PDP. As empresas do Grupo I, em geral, possuem apenas 1 equipe de projeto, as do Grupo II, uma média de 1,7 equipe e as do Grupo III, 1,5 equipe. Nas empresas do Grupo III existem, em média, 6,9 funcionários por equipe, no Grupo II, 3,8 funcionários por equipe e no Grupo I, 3,6 funcionários.

Ao se analisar a forma como as atividades das equipes de projeto são conduzidas pelas empresas, observou-se que não há diferença entre os grupos, prevalecendo a estrutura matricial em todos.

Nos três grupos, as parcerias ao longo do PDP ocorrem principalmente com fornecedores e com usuários finais. Na Figura 5 observa-se um aumento no número de parceiros do Grupo I para o Grupo III. Também é possível verificar, na Tabela 4, que o Grupo III é o que possui parcerias em mais fases do PDP. De maneira geral, as etapas em que ocorrem as parcerias confirmam o foco das empresas, de todos os grupos, na macrofase de desenvolvimento do produto.

\section{Dimensão atividades e informações}

Conforme apresentado no Figura 1, do Grupo I para o Grupo III existe uma evolução no grau de estruturação das atividades do PDP nas empresas. Ao analisar a realização das atividades do PDP por macrofases, esta evolução também pode ser visualizada.

Tabela 3. Funcionários do PDP por grupo.

\begin{tabular}{lcc}
\hline Grupo & $\begin{array}{c}\mathbf{N}^{\mathbf{0}} \text { médio de } \\
\text { funcionários } \\
\text { no PDP }\end{array}$ & $\begin{array}{c}\text { \% média de funcionários } \\
\text { do PDP com formação } \\
\text { superior }\end{array}$ \\
\hline I & 3,5 & 17,0 \\
II & 5,7 & 26,0 \\
III & 9,4 & 31,0 \\
\hline
\end{tabular}

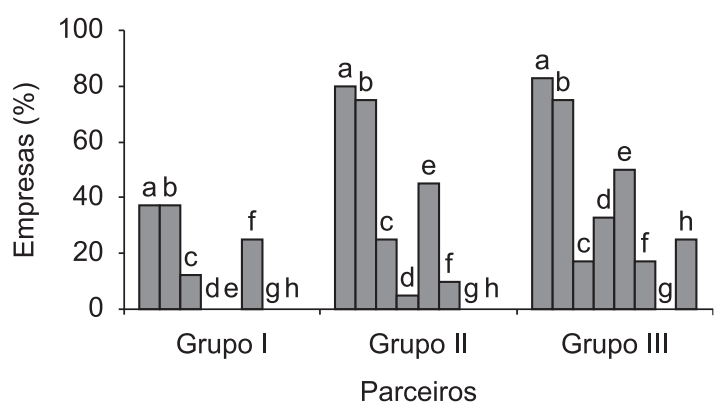

Figura 5. Parcerias no Processo de Desenvolvimento de Produto - PDP. (a: fornecedores; b: clientes usuários finais; c: clientes distribuidores; $\mathbf{d}$ : centros de capacitação e assistência técnica; e: universidades e institutos de pesquisa; f: empresas de consultoria; g: concorrentes; $\mathbf{h}$ : instituições de testes, ensaios e certificações).
No pré-desenvolvimento, as empresas do Grupo I ou não realizam as atividades desta macrofase ou as realizam de maneira informal. Nas empresas do Grupo II, essas atividades são realizadas predominantemente de maneira informal. As empresas do Grupo III, em sua maioria, realizam tais atividades de maneira formal (Figura 6).

Na macrofase de desenvolvimento, as empresas do Grupo I também realizam as atividades de maneira informal. As empresas dos Grupos II e III realizam tais atividades, predominantemente, de maneira formal (Figura 7).

No pós-desenvolvimento, as empresas dos Grupos I e II ou não realizam as atividades desta macrofase ou as realizam de maneira informal. No Grupo III, essas atividades são realizadas, predominantemente, de modo formal (Figura 8).

Assim, as empresas do Grupo I, de maneira geral, ou não realizam ou realizam de maneira informal as atividades das macrofases de pré-desenvolvimento e de pós-desenvolvimento, sendo que as atividades da macrofase de desenvolvimento são realizadas pela maioria das empresas deste grupo de maneira informal.

No Grupo II, as atividades de pré-desenvolvimento são realizadas, pela maioria das empresas, de maneira informal. As atividades de desenvolvimento são

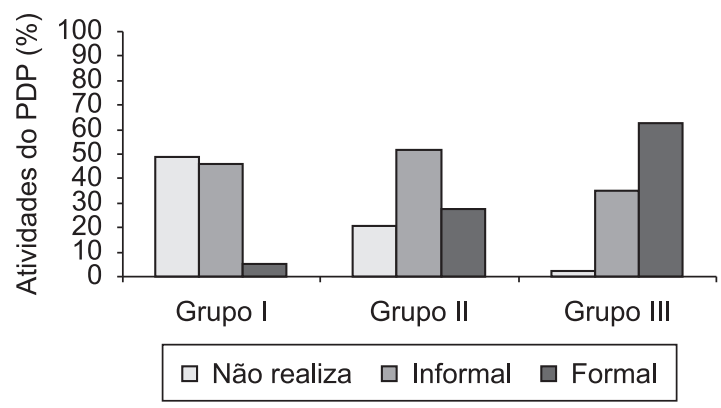

Figura 6. Grau de formalismo das atividades de pré-desenvolvimento.

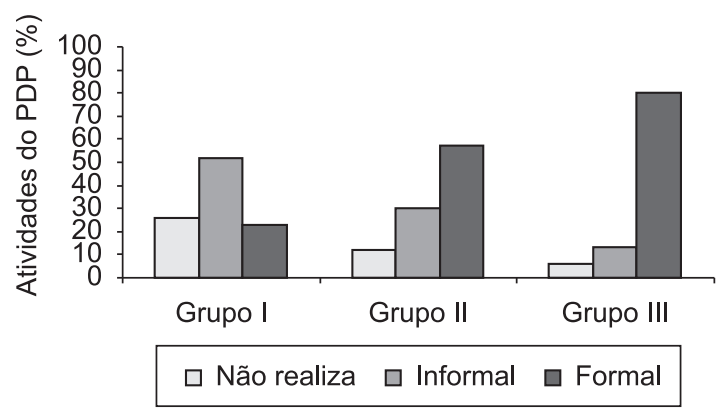

Figura 7. Grau de formalismo das atividades de desenvolvimento. 
Tabela 4. Fases do PDP em que a parceria é mais intensa. (PE: planejamento estratégico dos produtos; PP: planejamento do projeto; PI: projeto informacional; PC: projeto conceitual; PD: projeto detalhado; PrepProd: preparação para a produção; LP: lançamento do produto; AP: acompanhar produto/processo; DP: descontinuar produto).

\begin{tabular}{|c|c|c|c|c|c|c|c|c|c|}
\hline & & \multicolumn{8}{|c|}{ Parceiros } \\
\hline & & 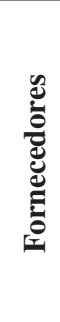 & 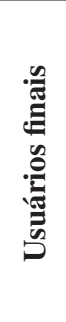 & 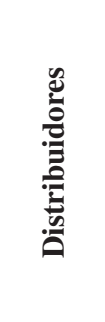 & 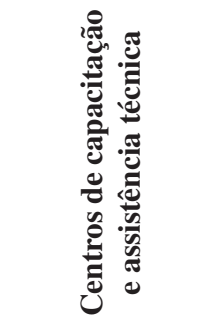 & 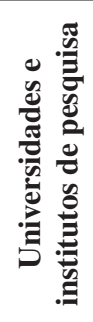 & 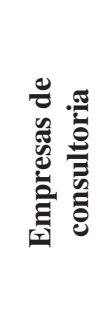 & 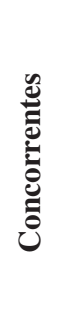 & 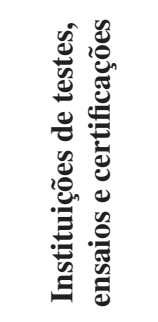 \\
\hline \multirow[t]{2}{*}{ Grupo I } & $\begin{array}{l}\text { Fases do PDP em que a } \\
\text { parceria é mais forte }\end{array}$ & PD & PD & PE & & & PD & & \\
\hline & $\%$ de empresas & 25 & 25 & 13 & & & 13 & & \\
\hline \multirow[t]{2}{*}{ Grupo II } & $\begin{array}{l}\text { Fases do PDP em que a } \\
\text { parceria é mais forte }\end{array}$ & PD & PD & PD & PD & PD & $\mathrm{PC}$ & & \\
\hline & $\%$ de empresas & 35 & 50 & 15 & 5 & 30 & 5 & & \\
\hline \multirow[t]{2}{*}{ Grupo III } & $\begin{array}{l}\text { Fases do PDP em que a } \\
\text { parceria é mais forte }\end{array}$ & PD & PD & PE, AP & PE, PP, PD, LP & PD & PE, PD & & $\mathrm{PC}, \mathrm{PD}, \mathrm{AP}$ \\
\hline & $\%$ de empresas & 50 & 50 & 8 & 8 & 25 & 8 & & 8 \\
\hline
\end{tabular}

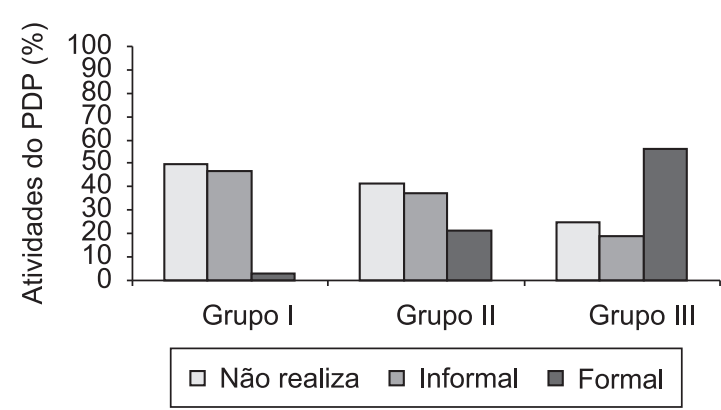

Figura 8. Grau de formalismo das atividades de pós-desenvolvimento.

realizadas predominantemente de maneira formal e as atividades de pós-desenvolvimento ou não são realizadas ou são realizadas de maneira informal.

No Grupo III, as atividades das três macrofases são realizadas de maneira formal pela maioria das empresas.

A existência de procedimentos formalizados para as atividades do PDP é observada, principalmente, nas empresas do Grupo III (58\% das empresas). No Grupo I, nenhuma empresa formaliza essas atividades e no Grupo II apenas 5\% das empresas as formalizam.

A realização de reuniões formais para avaliação por equipes multifuncionais das atividades desenvolvidas ao longo do PDP é feita somente por empresas do Grupo III (50\% das empresas deste grupo). Em 75\% das empresas do Grupo I e em $80 \%$ das empresas do
Grupo II, essas avaliações são realizadas de maneira informal, e nas demais não são realizadas, ficando essas decisões centralizadas no proprietário.

A existência de mecanismos formais de registro das experiências realizadas no projeto desenvolvido (lições aprendidas) é observada em $42 \%$ das empresas do Grupo III, em 20\% das empresas do Grupo II e em nenhuma do Grupo I.

\section{Dimensão recursos}

Quanto aos métodos e ferramentas de suporte ao PDP utilizados pelas empresas, observa-se que o CAD é o mais utilizado pelas empresas dos três grupos. O Benchmarking de produto é utilizado por 50\% das empresas do Grupo III (Tabela 5). Observa-se também que a quantidade de ferramentas e métodos de apoio ao PDP que não são conhecidos pelas empresas diminui do Grupo I para o Grupo III. De modo geral, pode-se afirmar que os métodos e ferramentas do PDP são pouco conhecidos pelas empresas.

\subsection{Mudanças, problemas e tendências}

Nos 3 anos anteriores à realização das entrevistas ocorreram mudanças significativas no PDP em apenas $25 \%$ das empresas do Grupo I, em cerca de $80 \%$ das do Grupo II e em todas as empresas do Grupo III. As principais mudanças no PDP das empresas do Grupo I foram a informatização e a terceirização de atividades do PDP; no Grupo III, foram a informatização e 
alteração na forma de organizar o trabalho das pessoas (equipes) durante a execução dos projetos. No Grupo II, as mudanças foram: informatização, terceirização e a forma de organização das equipes.

Quanto aos principais problemas enfrentados nos 3 anos anteriores, as empresas dos Grupos II e III declararam apresentar maiores problemas relacionados à qualidade do projeto e ao tempo de conclusão, além de problemas com qualificação do pessoal. Nas empresas do Grupo I, além dos problemas com qualidade e prazos, somam-se os problemas com o custo do desenvolvimento (Tabela 6).

Outros problemas enfrentados, na percepção das empresas do Grupo II, são: a instabilidade econômica do setor, que aumenta os riscos do lançamento de novos produtos, e a dificuldade de priorizar e decidir sobre idéias de novos produtos. No Grupo III, outros problemas citados foram: a estrutura de administração familiar e a grande quantidade de projetos conduzidos simultaneamente na empresa.

Quanto às tendências para o PDP apontadas pelas empresas, observa-se que embora em todos os grupos destaque-se a tendência de ampliação da capacidade própria de desenvolvimento de produto, somente no Grupo III há preocupação maior com melhoria da capacitação gerencial desse processo, o qual apontou como uma das principais tendências a implantação de novas ferramentas e métodos de apoio à gestão do PDP, incorporação de inovações tecnológicas nos produtos e aumento na taxa de lançamento de novos produtos (Tabela 7).

\subsection{Síntese}

O conjunto das PMEs de MIAs do Estado de São Paulo não pode ser considerado um grupo homogêneo em relação a gestão do PDP. São evidentes as diferenças existentes na gestão desse processo, principalmente entre os Grupos I e III. O Grupo II pode ser considerado um grupo de empresas em transição na maturidade do PDP, onde ora as empresas apresentam características similares às do Grupo I, ora semelhantes às do Grupo III.

No entanto, apesar das diferenças na gestão do PDP entre os três grupos de empresas, de acordo com os modelos de maturidade para o PDP prescritos na bibliografia da área, observa-se que as empresas encontram-se no Nível 1 (Básico) de maturidade, alterando-se apenas o subnível no qual se encontram.

Assim, pode-se dizer que as empresas do Grupo I enquadram-se no subnível 1.1, no qual as atividades do PDP, quando existentes, são realizadas de maneira informal, utilizando como método de apoio apenas o CAD em seus procedimentos mais simples.

As empresas do Grupo II se enquadram no subnível 1.2, uma vez que nessas empresas já se

Tabela 5. Ferramentas e métodos de suporte ao PDP por grupo.

\begin{tabular}{lcccccc}
\hline & \multicolumn{2}{c}{ \% de empresas que utilizam } & \multicolumn{2}{c}{ \% de empresas que não conhecem } \\
\hline & Grupo I & Grupo II & Grupo III & Grupo I & Grupo II & Grupo III \\
\hline Benchmarking & 0 & 30 & $50^{1}$ & $87,5^{2}$ & $55^{2}$ & 25 \\
QFD & 0 & 5 & 0 & $87,5^{2}$ & $70^{2}$ & $75^{2}$ \\
Engenharia do valor & 0 & 10 & 8,3 & $75^{2}$ & $60^{2}$ & $66,7^{2}$ \\
FMEA & 0 & 5 & 8,3 & $87,5^{2}$ & $65^{2}$ & $50^{2}$ \\
DFMA & 0 & 5 & 0 & $87,5^{2}$ & $70^{2}$ & $75^{2}$ \\
CAD & $87,5^{1}$ & $90^{1}$ & 83,31 & 12,5 & 0 & 0 \\
CAM & 0 & 35 & 33,3 & $50^{2}$ & 15 & 25 \\
PDM & 0 & 10 & 8,3 & $87,5^{2}$ & $75^{2}$ & 41,7 \\
Prototipagem rápida & 0 & 10 & 33,3 & $75^{2}$ & 40 & 33,3 \\
Técnicas de simulação & 12,5 & 35 & 33,3 & $62,5^{2}$ & 25 & 16,7 \\
GED & 25 & 5 & 33,3 & $75^{2}$ & $70^{2}$ & 33,3 \\
\hline
\end{tabular}

${ }^{1}$ pelo menos $50 \%$ das empresas a utiliza; ${ }^{2}$ pelo $50 \%$ das empresas não os conhece.

Tabela 6. Problemas enfrentados pelas empresas ao longo do PDP, por grupo.

\begin{tabular}{|c|c|c|c|c|c|c|c|c|}
\hline \multirow[b]{2}{*}{ Grupo } & \multicolumn{8}{|c|}{ Problemas enfrentados no PDP (\% de empresas) } \\
\hline & Qualidade & Prazos & Custos & $\begin{array}{l}\text { Recursos } \\
\text { humanos }\end{array}$ & $\begin{array}{l}\text { Práticas de } \\
\text { gestão }\end{array}$ & Informação & $\begin{array}{c}\text { Colaboração } \\
\text { no DP }\end{array}$ & Outros \\
\hline I & 25 & 25 & 25 & 0 & 0 & 13 & 13 & 0 \\
\hline II & 20 & 25 & 5 & 25 & 5 & 10 & 5 & 5 \\
\hline III & 33 & 33 & 0 & 17 & 0 & 0 & 0 & 17 \\
\hline
\end{tabular}


Tabela 7. Tendências do Processo de Desenvolvimento de Produto - PDP, por grupo.

\begin{tabular}{lccc}
\hline \multicolumn{1}{c}{ Tendências } & $\begin{array}{c}\text { Grupo I } \\
\text { (\% de empresas) }\end{array}$ & $\begin{array}{c}\text { Grupo II } \\
\text { (\% de empresas) }\end{array}$ & $\begin{array}{c}\text { Grupo III } \\
\text { (\% de empresas) }\end{array}$ \\
\hline Ampliação da capacidade própria de DP & $63^{1}$ & $55^{1}$ & $67^{1}$ \\
Redução da capacidade própria de DP & 13 & 10 & 8 \\
$\begin{array}{l}\text { Aumento da adoção de inovaçães } \\
\text { tecnológicas nos produtos }\end{array}$ & 38 & $70^{1}$ & $67^{1}$ \\
$\begin{array}{l}\text { Aumento da adoção de inovaçães } \\
\text { tecnológicas nos processos }\end{array}$ & $63^{1}$ & $60^{1}$ & 42 \\
$\begin{array}{l}\text { Aumento da frequência de lançamentos } \\
\text { de novos produtos }\end{array}$ & $50^{1}$ & 45 & $67^{1}$ \\
$\begin{array}{l}\text { Novas formas de organização do processo de DP } \\
\text { Implantação de novas ferramentas ou } \\
\text { métodos de apoio à gestão do PDP }\end{array}$ & 25 & 35 & 42 \\
$\begin{array}{l}\text { Implementação ou ampliação das } \\
\text { parceiras no PDP com fornecedores }\end{array}$ & 13 & 35 & $67^{1}$ \\
$\begin{array}{l}\text { Implementação ou ampliação das parceiras } \\
\text { no PDP com clientes usuários finais }\end{array}$ & 25 & 35 & 42 \\
$\begin{array}{l}\text { Implementação ou ampliação das parceiras } \\
\text { no PDP com clientes distribuidores }\end{array}$ & 13 & 30 & 33 \\
$\begin{array}{l}\text { Implementação ou ampliação das parceiras com } \\
\text { universidades e institutos de pesquisa }\end{array}$ & 13 & 20 & 17 \\
$\begin{array}{l}\text { Implementação ou ampliação das parceiras } \\
\text { no PDP com empresas de consultoria }\end{array}$ & 0 & $50^{1}$ & \\
$\begin{array}{l}\text { Implementação ou ampliação das parceiras no PDP } \\
\text { com centros de capacitação e assistência técnica }\end{array}$ & 0 & 10 & $50^{1}$ \\
$\begin{array}{l}\text { Implementação ou ampliação das parceiras com } \\
\text { instituições de testes e certificações }\end{array}$ & 0 & 20 & 17 \\
\hline 1 pelo menos 50\% das empresas. & & & 25 \\
\hline
\end{tabular}

começa a visualizar uma maior preocupação com a realização das atividades de pós-desenvolvimento, embora estas ocorram, em sua maioria, de maneira informal. As atividades relativas à macrofase de desenvolvimento são realizadas, em sua maioria, de maneira formal, embora algumas atividades, tais como produção de lote piloto, homologação do produto, desenvolvimento de processo de assistência técnica, acompanhamento do desempenho dos novos produtos em uso no mercado, entre outras, sejam ainda realizadas predominantemente de maneira informal.

As empresas do Grupo III se enquadram no subnível 1.4, no qual as atividades do PDP são realizadas, predominantemente, de maneira formal. Além disso, algumas atividades específicas e que representam maior maturidade no gerenciamento do PDP já começam a ser realizadas, tais como eventos para análise e aprovação de fases (gates) e registro das lições aprendidas ao longo do projeto. No entanto, o uso de indicadores para mensurar o desempenho dos projetos e do PDP ainda é incipiente nas empresas deste grupo, assim como a utilização de ferramentas e métodos de apoio ao PDP.

\section{Considerações finais}

Agrupando-se as empresas por nível de maturidade da gestão do PDP, considerando o grau de formalização das atividades realizadas ao longo deste processo, realizou-se uma análise de cluster, da qual resultaram três grupos de empresas. Isso permitiu identificar os perfis da gestão do PDP nas PMEs do setor.

A definição do nível de maturidade em que se encontram as PMEs do setor no Estado de São Paulo, além de proporcionar um diagnóstico das práticas do PDP, auxilia as empresas na determinação de oportunidades para melhoria do seu processo de desenvolvimento. Essa identificação do nível de maturidade também pode auxiliar no estabelecimento de políticas públicas específicas para cada realidade, 
no caso, os grupos e perfis identificados das empresas.

A partir do diagnóstico realizado por meio da pesquisa de campo e da organização de um workshop de discussão dos resultados com representantes das empresas, foi possível apontar recomendações de melhoria para as empresas e, principalmente, por sugestão destas também foram identificadas ações que poderiam ser empreendidas por entidades públicas ou do próprio setor.

Assim, com o intuito de auxiliar as empresas na melhoria do seu PDP, sugere-se que as empresas o Grupo I:

- invistam na melhoria de seus processos produtivos, uma vez que isto permitirá que desenvolvam produtos com maior nível de inovação e/ou complexidade e possíveis de serem manufaturados pela empresa que, assim, as tornem mais competitivas e atuantes nos mercados nacional e internacional; e

- incentivem a melhoria da capacitação técnica e gerencial dos funcionários e proprietários, a fim de adquirirem características de gestão mais profissional, tornando-se mais estruturadas e aprimorando sua visão de perspectivas futuras, o que contribuirá para a melhor estruturação e desempenho de seus PDPs.

Para as empresas do Grupo III, sugere-se:

- investimentos em inovações tecnológicas de produto, capacitando-as para o desenvolvimento de produtos diferenciados, com maiores condições de competitividade nos mercados interno e externo;

- incentivo à participação de seus profissionais em feiras e congressos nacionais e internacionais do setor, o que permitiria um maior conhecimento das tecnologias já existentes e das tendências futuras; maior aproximação com universidades e centros de pesquisa com atuação na área de MIA, para viabilizar a adequação e adoção de inovações tecnológicas, contribuindo para que produtos inovadores sejam desenvolvidos por estas empresas; e

- incorporação de métodos de apoio ao gerenciamento individual e integrado de projetos.

As empresas do Grupo II poderiam se beneficiar com as diretrizes de melhoria para os Grupos I e III.

No entanto, para que tais diretrizes consigam atingir as PMEs do setor elas devem ser intensamente divulgadas e operacionalizadas com níveis de burocratização e complexidade reduzidos. Essas diretrizes podem ser discutidas no âmbito das empresas e de órgãos de financiamento e de fomento tecnológico, além de em entidades setoriais, como, por exemplo, a ABIMAQ, gerando possíveis políticas públicas de incentivo. É importante também atentar para a constatação de Guerrero (2003), segundo o qual a falta de divulgação e o excesso de burocratização são os maiores empecilhos para a adesão das PMEs a políticas de incentivo governamentais.

Além dessas diretrizes, conforme resultado do workshop realizado, outras medidas também poderiam proporcionar melhorias no PDP dessas empresas:

- maior participação das empresas de MIAs em associações setoriais, como a ABIMAQ, o que poderia auxiliar no levantamento e obtenção de informações técnicas e de mercado confiáveis para as empresas do setor e contribuir para o maior intercâmbio de experiências entre elas;

- desenvolvimento de atividades de padronização das nomenclaturas e especificações relacionadas aos produtos e projetos no setor de MIAs;

- elaboração, por acadêmicos e profissionais interessados no setor, de um modelo prático para gestão do PDP adequado à realidade e necessidades dessas empresas, a ser validado e difundido entre as empresas do setor; e

- implantação de planos para a consolidação no país de uma diretriz e de infraestrutura para homologação e certificação de produtos.

As características gerais das PMEs do setor de MIAs, tais como a escassez de recursos financeiros, a insuficiência de recursos humanos e deficiências no modo de gestão empresarial, entre outras, devem ser consideradas na formulação das ações e propostas para melhoria da gestão do PDP a fim de que sejam atendidas as reais necessidades dessas empresas.

Espera-se que essa caracterização dos perfis da gestão do PDP nas PMEs de capital nacional do setor de MIAs do Estado de São Paulo possa contribuir como subsídio a ações de melhoria do desenvolvimento de produto, assim como para a elaboração de políticas públicas de incentivo à inovação e desenvolvimento de produto nessas empresas.

\section{Referências}

Associação Brasileira da Indústria de Máquinas e Equipamentos - ABIMAQ. Indicadores conjunturais: indústria de máquinas e implementos agrícolas. São Paulo: FIESP, 2005.

Associação Brasileira da Indústria de Máquinas e Equipamentos - ABIMAQ. Desempenho do setor. 2006. Disponível em: <http://www.anuarioabimaq. com.br/>. Acesso em: 19 abril 2006.

AMATO NETO, J. A indústria de máquinas agrícolas no Brasil: origens e evolução. In: ENCONTRO NACIONAL DE ENGENHARIA DE PRODUÇÃO - 
ENEGEP, 4., 1984, Piracicaba. Anais... Piracicaba, 1984. p. 76-110.

BRASIL. Ministério do Planejamento, Orçamento e Gestão. Instituto Brasileiro de Geografia e Estatística - IBGE. Pesquisa Nacional de Inovação Tecnológica (PINTEC 2003). Disponível em: <www.ibge.gov.br>. Acesso em: 20 abril 2005.

BRASIL. Ministério da Agricultura, Pecuária e Abastecimento - MAPA. Modernização. 2004. Disponível em: <www.agricultura.gov.br>. Acesso em: 09 agosto 2005.

BRASIL. Ministério da Ciência e Tecnologia - MCT. Competitividade da indústria de máquinas agrícolas. 1993. Disponível em: <http://ftp.mct.gov.br/publi/ Compet/nts_ima.pdf>. Acesso em: 20 maio 2006.

BRASIL. Ministério da Ciência e Tecnologia - MCT. Estudo de importação de equipamentos e materiais para o setor de máquinas e implementos agrícolas no Brasil. Brasília: Embrapa trigo, 2006

BRASIL. Ministério do Desenvolvimento, Indústria e Comércio Exterior. Banco Nacional de Desenvolvimento Economico e Social - BNDES. Máquinas e implementos agrícolas. 1995. Disponível em: <http://www.bndes. gov.br/conhecimento/setorial/get4_is2.pdf >. Acesso em: 12 junho 2006.

CHENG, L. C. Caracterização da gestão de desenvolvimento de produto: delineando o seu contorno e dimensões básicas. In: CONGRESSO BRASILEIRO DE GESTÃO DE DESENVOLVIMENTO DE PRODUTO, 2., 2000, São Carlos. Anais... São Carlos: IGDP, 2000.

CHRISSIS, M. B.; KONRAD, M.; SHRUM, S. CMMI: Guidelines for process integration and product improvement. Boston: Addison-Wesley, 2003

CLARK, K. B.; FUJIMOTO, T. Product development performance: strategy, organization and management in the world auto industry. Boston: HBS Press, 1991.

CONFEDERAÇÃO DA AGRICULTURA E PECUÁRIA DO BRASIL - CNA; CENTRO DE ESTUDOS AVANÇADOS EM ECONOMIA APLICADA - CEPEA.
PIB do agronegócio. 2005. Disponível em: <http://www. cepea.esalq.usp.br/pib>. Acesso em: 22 junho 2006

GUERRERO, A. E. A. Programas de apoio governamentais: uma estratégia para a gestão de desenvolvimento de produto nas PMEs industriais. In: CONGRESSO BRASILEIRO DE GESTÃO E DESENVOLVIMENTO DE PRODUTOS, 4., 2003, Gramado. Anais... Gramado: UFRGS, 2003.

KAHN, K. B.; BARCZAK, G.; MOSS, R. Dialogue on best practices in new product development perspective: establishing an NPD best practices framework. Journal of Product Innovation Management, v. 23, n. 2, p. 106-116, 2006.

PRODUCT DEVELOPMENT AND MANAGEMENT ASSOCIATION - PDMA. Knowledge areas. 2005. Disponível em: <http://www.pdmabok.org/>. Acesso em: 02 setembro 2007

ROMANO, L. N. Modelo de referência para o processo de desenvolvimento de máquinas agrícolas. 2003. 321 f. Tese (Doutorado) - Universidade Federal de Santa Catarina, Florianópolis, 2003.

ROZENFELD, H.; AMARAL, D. C.; TOLEDO, J. C. O processo de desenvolvimento de produto na fábrica do futuro. In: ROZENFELD, H. A fábrica do futuro. São Paulo: Banas, 2000.

ROZENFELD, H. et al. Gestão de desenvolvimento de produtos: uma referência para a melhoria do processo. São Paulo: Saraiva, 2006.

TOLEDO, J. C. et al. Gestão do processo de desenvolvimento de produto em empresas de base tecnológica de pequeno e médio porte do Estado de São Paulo: diagnóstico e proposição de modelo de referência. São Carlos: Departamento de Engenharia de Produção - UFSCar, 2006. 389 p. Relatório de pesquisa FAPESP.

WHEELWRIGHT, S. C. W.; CLARK, K. B. Revolutionizing product development: quantum leaps in speed, efficiency, and quality. New York: The Free Press, 1992. 